Article

\title{
Analysis of Sheet Metal Tapping Screw Fabrication Using a Finite Element Method
}

\author{
Shao-Yi Hsia ${ }^{1, *}$, Yu-Tuan Chou ${ }^{2}$ and Guan-Fan Lu ${ }^{1}$ \\ 1 Department of Mechanical \& Automation Engineering, Kao-Yuan University, Kaohsiung City 821, Taiwan; \\ guan.fan.lu@gmail.com \\ 2 Department of Applied Geoinformatics, Chia Nan University of Pharmacy \& Science, \\ Tainan City 717, Taiwan; ytchou@mail.cnu.edu.tw \\ * Correspondence: syhsia@cc.kyu.edu.tw; Tel.: +886-7-607-7777 (ext. 2103); Fax: +886-7607-7112
}

Academic Editor: Teen-Hang Meen

Received: 20 June 2016; Accepted: 8 October 2016; Published: 18 October 2016

\begin{abstract}
The malformation of sheet metal tapping screw threads in the screw threading process increases the cost of screw threading dies and their maintenance. Die factories do not reveal their screw threading die design techniques, so production and maintenance processes are established by trial-and-error or worker experience and passing down such techniques and documenting quality control is difficult. In this study, screw thread forming design and process analysis were carried out by combining computer-aided design software with computer-aided metal forming analysis software. Simulation results were verified in an actual forming process. The sheet metal tapping screw forging size error was less than $0.90 \%$, except at a sharp angle, which was associated with an error of $3.075 \%$, thereby demonstrating the accuracy of the simulated forming process. The numerical analysis process can be utilized to shorten forming development time; to reduce the number of die tests, and to improve product quality and die service life, reducing the cost of development and promoting the overall competitiveness of the company.
\end{abstract}

Keywords: sheet metal tapping screw; screw threading die; computer aided design; computer aided metal forming analysis

\section{Introduction}

Screw threading has various origins, and has a recorded history that goes back to "Before the Common Era". After the Industrial Revolution in England began in the late Eighteenth Century, screw threads of various sizes were manufactured by various methods under various production policies. The domestic screw industry developed over a long period of time. Many people regard screws as a result of simple engineering, but their development is truly remarkable. The screw industry systematically classifies its products, the name of which has changed from screws to fasteners. Small screws may seem unimportant, but they provide great economic value. Following the development of screw technology, international competition has become fierce. Taiwan's domestic screw industry is currently encountering competitors and pursuers: Japan is a representative competitor and mainland China is a representative pursuer.

Although many methods for producing a screw exist, improvements in screw blanks and advances in steelmaking have left people wondering about changes in screw threading over the last decade. Although the future of the industry is not known, the trial-and-error method is no longer competitive. Given international free trade, a foothold in a dynamic market can be ensured only by embracing accurate, rapid, and effective "innovation" models. 


\subsection{Research Motivation}

The flat-die thread rolling process is widely utilized in the screw industry. Although several varieties of screws add to difficulties in design and manufacturing, domestic thread flat-die manufacturers use various production technologies, which they keep confidential. Owing to social and cultural changes, today's youth appears to have little desire to engage in traditional industries. Also, a general over-investment in Taiwan's screw "specification products" has resulted in little uniqueness and low added value, resulting in a lack of competitiveness in the global market. Moreover, Taiwan's population is rapidly ageing and exhibits sub-replacement fertility, as does Japan, so the fastener industry should actively pursue the production of high value-added and high-quality products and improve its production technology by enhancing product research and development.

This investigation focuses on cone bolt (CB) screw thread plates (Figure 1), which are an important product. It suggests a new sheet metal thread plate design using SolidWorks (2012 Edition SP0, SolidWorks, Concord MA, USA) computer-aided design software and DEFORM-3D (V6.1, Scientific Forming Technologies Corporation, Columbus, OH, USA) finite element forming analysis software to reduce errors during die manufacturing. The results thus obtained not only improve die design efficiency but also reduce production costs. Thus, a practicable manufacturing method is developed and validated using real products. The study of new thread plates depends on solutions to the following problems.

(a) Recruiting specialists in thread plate design is difficult and this traditional industry can hardly survive in the current environment. Also, current salaries are not generally attractive to qualified professionals.

(b) The shortage of CAD and CAE designers is a significant problem for businesses that seek to increase the value provided by screws without giving away trade secrets. This dilemma is real, as newly developed products may involve a complicated thread for which a thread flat-die manufacturer must develop a mold, the existence of which may result in the sharing of confidential data.

(c) A complicated thread form cannot be easily simulated using CAD and forming analysis software. Training designers using the feedback design curve, based on the experience of a mold manufacturer, takes a long time and is costly, and is unacceptable to the industry.

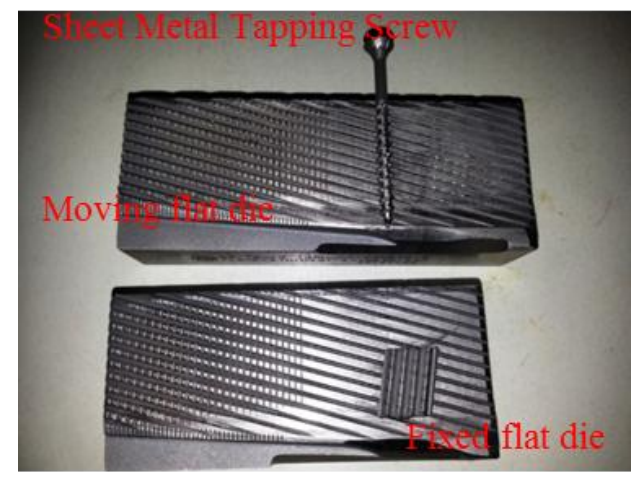

Figure 1. Cone bolt (CB) thread and screw thread plate.

Promoting research and development in screw products directly improves the competitiveness of the industry, but the ability to pass along technological knowledge to future workers is worsening. Farsighted corporations therefore record their design and process technologies and promote R\&D, SOP (Standard Operation Procedure), and various process improvement programs to prevent them from being monopolized by only a few designers. Therefore, this work designs, develops and analyzes a 
thread flat-die using both SolidWorks computer-aided design software and DEFORM-3D finite element forming analysis software, and verifies the practicability of the die thus produced.

\subsection{Literature Review}

The finite element method can be utilized to analyze simultaneously all mechanical problems that are associated with the interface between a die and blank under plastic deformation. Theoretically, the geometric complexity of the simulated object is unlimited. The advance of technology in recent years has rapidly increased the speed of computers. The development of simulation and analysis software has matured and stabilized, so the finite element method is more efficient and accurate than ever before. The application of the finite element method to forging is discussed below.

Connell et al. [1] developed DEFORM-2D, the slab method and the finite element method in 1996 to estimate the forming load in hexagon-head screw flashless closed-die forging with the purpose of suitable forming machines, reducing the energy consumption, and increasing the production rate. Kim and Altan [2] used FORMEX and DEFORM finite element software in the same year to establish a process program database for a part design forming process and effectively reduced the order and die design time in production. Also in that year, Liou and Jang [3] combined the Taguchi method with the finite element method in a radial forging analysis to find optimal process conditions that minimize residual stress, because residual stress causes the geometric deformation of forges and some related materials. A corrosive environment damages dies via stress corrosion.

To reduce the forming load in closed-die forging and prevent short filling or laciniate line, in 1998, Joun et al. [4] utilized penalty rigid viscoplastic finite element algorithms to add a die plate to the radial of reflection-symmetric forming dies with a spring at the bottom to enable the moveable forming die to self-adjust its displacement during blank flow as the material is filling the mold. Thus, they markedly reduced the friction and forming load, while providing uniform streamlining of material that enhanced the quality of forges. In the same year, Vazquez et al. [5] used DEFORM finite element software to compare a tungsten carbide loading die with a split loading die for cold forging and they examined the effects of the material on the service life of the dies; their ultimate goal was to find the best method for extending die service life. As well as reducing the cost of forging dies, they analyzed the service life of cold forging dies.

In 2001, Falk et al. [6] utilized DEFORM finite element software to develop a method that was related to forge volume. It easily and accurately estimated the service life of forging dies, as was verified experimentally. In 2002, Janiceka et al. [7] utilized ANSYS finite element software to reduce the number successive heat treatments following cold forging to achieve the required strength of cold-processing bolts that were made from specially designed 8Mn2Si micro-alloy steel. In 2003, Min and Kim et al. [8] used DEFORM-3D finite element analysis software to perform a multi-pass forming analysis of automobile turning connectors, subsequently proposing a new process for improving the properties of these products, production efficiency, development time, and costs. This work was successfully exploited to mass production. In 2004, Liu et al. [9] utilized DEFORM-3D to combine forging with the establishment of nuts specifically for tyres, and analyzed to identify the factors that affect punch destruction. Their results revealed that an unreasonable punch size affects metal flow and increases the axial tensile stress of the punch as it exits the nut hole. In 2004, Sofuoglu and Gedikli [10] used physical modeling and ANSYS Finite Element to analyze the variation of the internal grid of a blank with the extrusion rate (R) and die extrusion half angle $(\alpha)$ in the 3D extrusion process as well as the variation of the extrusion load with the punch displacement.

In 2004, Kim et al. [11] used AUTOCAD's auto-writing function (LISP) with DEFORM and ANSYS to develop an automatic process planning and die design system that could be used to design multi-pass bolt-forming products. The system was established by combining plastic theory, experimental results, and the research design rules and experiences of experts. The planning process and die design module took into account complicated punch and die shapes, available multi-pass forming, and available standard parts. The system effectively reduced the time that engineers required 
to determine the diameter and height of an original blank and reduced the time required to form the shapes of the final products. In 2007, Kim [12] utilized CAMPform-3D to analyze cold forging tail pins, and replaced original welding with extrusion and upsetting to obtain results that were consistent with those of the cold forging experiment for mass production. In the same year, Jun et al. [13] utilized the finite element method to predict the geometry of cold forges and elucidated the problems of deformation, spring-back, and heat shrinkage by analyzing material SCM420H and die material SKD11. They utilized this method to test whether the effects of rising temperatures on die material could be ignored in the cold forging process.

In 2008, Lv et al. [14] utilized 3D finite elements to simulate a multi-pass turbo-compressor blade forging process. Their simulation successfully predicted the complete load/time curve and the deformation structure whilst performing, as well as the material flow, strain, and temperature distribution. They also carried out experiments to optimize the process parameters and proved that the optimal process parameters effectively reduced product fragility and provided favorable mechanical properties (strength and ductility).

In 2015, Hsia [15] utilized the finite element method to analyze and simulate the forming load of movable retaining pins at each stage, and the Taguchi method to optimize the quality of products in the key second stage. Their analytical results demonstrated that converting the original three forging processes and one drilling process into four forging stages solves the problems in the manufacturing of parts. In the same year, Hsia and Shih [16] used finite element analysis to simulate wear in automotive repair fastener manufacturing dies, based on actual process conditions. Applying the Taguchi quality method to the new design, they found a $19.87 \%$ improvement in wear.

In 2015, Landeta et al. [17] developed a method for estimating the wear of forming taps, which is useful for evaluating the performance of roll taps with hexagonal or pentagonal section geometry. They drew a useful conclusion for tap manufacturers that taps with a hexagonal section and five pitches in the chamfer zone generated lower thrust forces and torques and lower wear than those with a pentagonal section. Urbikain et al. [18] developed a new method for the rapid and economical production of 'nutless' bolted joins, by combining two hole-making techniques, namely, form-drilling and form-tapping. The combined method enabled the rapid production of threaded holes in coupled dissimilar metal alloys, such as steel and aluminum alloys. They also carried out corrosion tests to obtain a better understanding of the manufactured joint.

In summary, many researchers have investigated forming, bolts, and screw threading technologies, but no specific reference literature is available for academia or industry owing to the complicated shapes of screws or sheet metal nails. Accordingly, the goal of this investigation is to help businesses to establish a sheet metal thread design and analysis method using forming software that is matched with solid parameters and optimization.

\section{Fundamental Theory}

\subsection{Screw Thread Theory}

A screw thread can be regarded as a gently rolling inclination on a cylinder (Figure 2). The continuous bulges on the spiral inclination are "screw threads." The spiral lines on the outer surface of a cylinder or a cone are outer screw threads (bolts and studs) whereas the spiral lines on the surface of the cylindrical bore or the conical bore are inner screw threads (nuts and tapped holes). In Figure $2, d_{m}$ denotes pitch circle diameter; $P$ represents the pitch of the screw thread, and $\alpha$ is the spiral angle. A spiral line that rotates in a clockwise spiral is called a right screw thread and one that rotates in a counterclockwise spiral is called a left screw thread. 


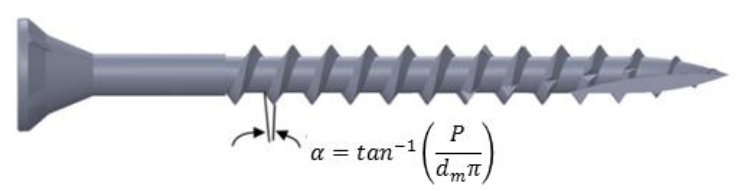

Figure 2. Screw thread spiral diagram.

\subsection{Brief Introduction to Flat-Die Thread Rolling}

Two methods can be used for screw thread rolling. One involves cutting parallel grooves on the surface of each mold between two flat dies, where the groove shape is the reverse of the screw threads. One mold is fixed and the other undergoes reciprocation with the workpiece (blank) between them. This process is called the flat-die thread rolling process, wherein the screw thread rolling die is composed of a fixed plate and a moving plate. The fixed plate is generally shorter (short thread plate) and the moving plate is longer (long thread plate) (Figure 3).

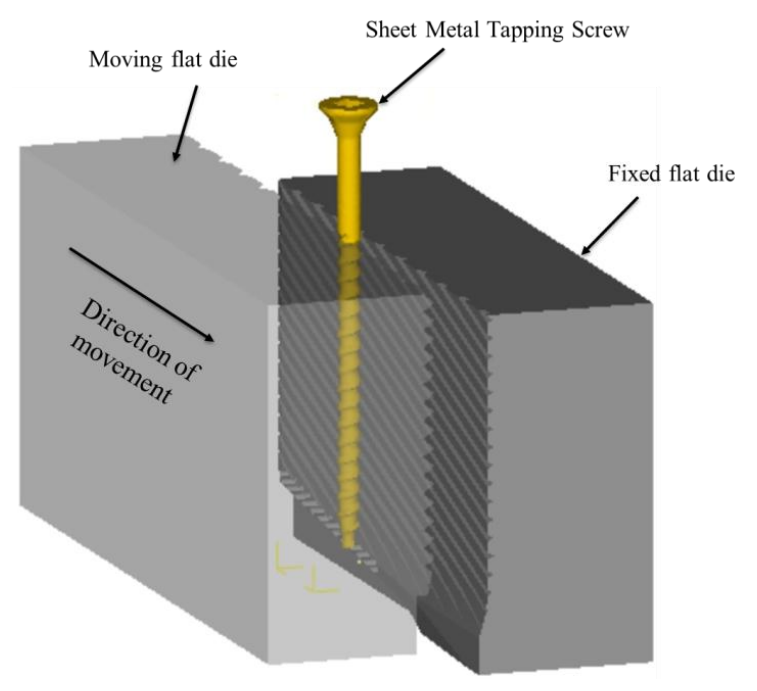

Figure 3. Flat-die thread rolling (with fixed flat die and moving flat die).

The other method involves a cylindrical roller mold with two or three grooves, and the rolling of the workpiece between the molds. When two roller molds are used, the workpiece between them is supported on a parallel holder and the right roller exerts pressure. When three rollers are used, three axes are parallel and synchronously rotated at appropriate speeds. The three rollers are operated by a cam while the workpiece is fed radially, and this process is called round mold thread rolling.

Flat-die thread rolling is a chipless cold-working precision forming process for producing screws. Cold forging is primarily utilized in mass production; hot forging is used to manufacture large screws and nuts, and cutting processing is utilized only to manufacture a few products with special specifications. The underlying principle is to apply proper pressure on a round rod blank between a rotating roller mold and a reciprocating plane mold during cold processing. The threads on the mold are the reverse screw threads of the workpiece. Rolled under pressure, the metal undergoes plastic flow and the bulged wedging mold compresses the bottom of the screw thread so that the metal is extruded along both sides to form the peak of the screw thread.

Screw thread rolling produces smoother surfaces than turning, milling, or grinding. It provides greater strength and hardness of the screw thread surface because of work hardening, high material utilization, and double the productivity of cutting processing; it is easily automated, and results in a long service life for dies. Nevertheless, the hardness of the workpiece material for rolling screw threads cannot exceed HRC40; the need for precise blank sizing is greater; the need for precise rolling and a hard die is greater; producing the dies is more difficult, and the process cannot be used to roll 
asymmetric screw threads. More than $90 \%$ of screws with diameters less than $50 \mathrm{~mm}$ are produced by rolling. In metal stretching tests, a $5 \mathrm{~cm}$ gauge length with $12 \%$ elongation exhibits excellent rollability and is suitable for the rolling process. Numerous metal characteristics, such as hardness, ductility, internal friction that is generated during plastic deformation, yield strength, and cold hardening, affect the plastic deformation and rollability of metals.

An automatic thread rolling machine completes a large deformation in a single operation. It provides a high production rate, but product defects and the short service life of the thread plate negatively affect productivity and production costs. As a result, a comprehensive understanding of the characteristics of process parameters through simulation would improve process design and quality evaluation. The blank material, surface quality, blank size, thread plate size, thread plate speed, thread flat-die geometry, interface lubricant, and service life of the thread plate all significantly influence the quality of the thread rolling product, its production cost, and its production efficiency.

\subsection{Geometric Construction of Screw and Thread Plate}

The characteristics of the cone bolt (CB) screw thread plate (Figure 4) are as follows.

(a) Feed-in area: the portion where a light nail is fed in and compressed in the turning process. The feed-in area and shaping area are often within carved slip teeth.

(b) Shaping area: the area where the light nail, after passing the feed-in area, is extruded and formed.

(c) Forming area: the area where the light nail, after passing the feed-in area and the shaping area, is extruded into screws, in a manner that is determined by the thread grooves of the thread plate, the thread peak, and the cone bolt angle.

(d) Discharge area: the portion where formed screws are discharged.

(e) Back angle and elevation angle: the portion where the cone bolt thread plate is cut to form the tip. The back angle controls the feed-in of the material in that a large back angle allows more material to be fed in and a small back angle reduces material feed. The elevation angle is the essential parameter in the forming of the thread tip and thread peak on the thread tip. Small elevation angles result in trailing as the tail is not cut cleanly. Larger elevation angles cause broken tips because the light nail is cut too early.

(f) Cut: crossing of the back angle and screw thread plate cone bolts. A sharp cut is required as a blunt cut results in trailing and inconsistent tip forming.

(g) Thread depth: depth of the screw thread peak, which controls the outer diameter of the screw.

(h) Crest angle: the angle of the screw thread peak. Specific screw crest angles are required to meet particular specifications; for example, a C/B chipboard nail has a crest of 40 degrees; a general BA round-tail screw has a crest of 47.5 degrees; a general triangular self-tapping thread has a crest of 45 degrees, and a general machine thread has a crest of 58 60 degrees. Crest angle is also critical in controlling the outer diameter of the screw.

(i) Cone bolt angle: screw tip angle. General self-tapping screw tips have angles of 40 50 degrees. Specific screws must meet particular specifications; for example, general wallboard nail and chipboard nail tips have angles of 20 30 degrees. Customers sometimes specify tip angles.

(j) Angle of chamfer: the feed-in area and shaping area that are milled sharply in the thread plate production process for easy feed-in. When the angle of chamfer is too small, the thread plate is not abrasion-resistant. When the angle of chamfer is too large, the tail feed-in area is too large, making screw forming difficult, and the outer diameter too small. When chamfer in the feed-in area is greatly worn, the screws are not sufficiently formed and the screw diameter will be too large to support slipping.

(k) Slip teeth: threads that are specially carved on the thread plate feed-in area and the forming area to prevent a light nail from slipping in the feed-in process. Shallow slip teeth cause slipping, while deep slip teeth result in roughened screw bottoms, dim thread peaks, and even blocking of the extrusion of light nails, causing the outer diameters of the screws to be too small. 
(l) Cone bolt height: the distance between the thread plate surface and the cut, which is generally half of the bottom diameter of the screw. Cone bolts that are too high cause the screw cut to bump together, causing insufficient screw forming. A cone bolt that is too low causes trailing because the tail is not cut off.

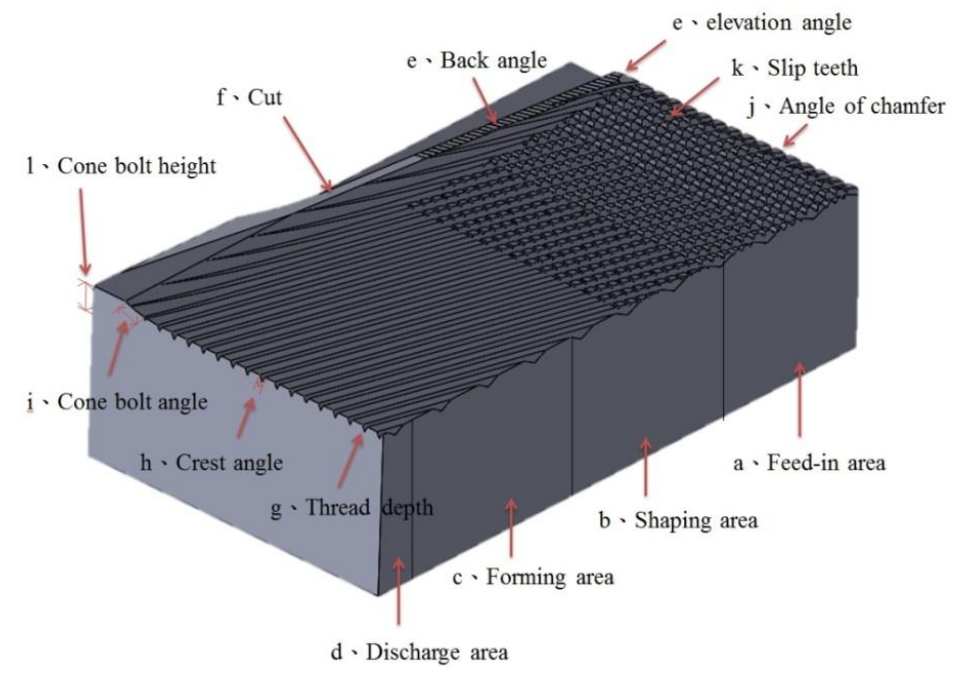

Figure 4. Parts of a thread plate.

\subsection{Mathematical Theory of DEFORM-3D}

The DEFORM-3D program was specifically designed to analyze 3D flows in various metal forming processes, and to provide valuable process data concerning material and temperature flows in forming processes. This software program is based on the finite element method (FEM), and can be used in other fields. For example, it can be used to generate a numerical model of ball-burnishing to understand and predict residual stress values and their variation with process parameters. Typical DEFORM-3D applications are plastic processing during forging, extrusion, calendaring, open-die forging, and flexure. The software is also frequently utilized in the aerospace, automobile, and screw-and-nut industries to analyze complex forging processes.

Based on the revised Lagrange's Theory, DEFORM is a rigid-plastic FEM. The FEM formulation, using "the variation principle," is used for rigid plastic material, and its function is as follows.

$$
\pi=\int_{V} \dot{\sigma \varepsilon} d V-\int_{S_{F}} F_{i} u_{i} d S
$$

where $\bar{\sigma}$ is effective stress, $\dot{\bar{\varepsilon}}$ is the effective strain rate, $F_{i}$ is surface tractions, and $V$ and $S$ are volume and surface of the deforming workpiece, respectively. The solution to the original boundary-value problem is then acquired from the solution of the dual-variation problem. When applying the penalty method, velocity is the primary solution variable. The variation equation is

$$
\delta \pi(V)=\int_{V} \bar{\sigma} \delta \dot{\bar{\varepsilon}} d V+k \int_{V} \dot{\varepsilon}_{V} \delta \dot{\varepsilon}_{V} d V-\int_{S_{F}} F_{i} \delta u_{i} d S
$$

where $k$ is the penalty constant, and $\dot{\varepsilon}_{V}$ is the volumetric strain rate.

Equation (1) and its derived formulations can be converted into a set of algebraic equations by the standard FEM discretization procedures. Here DEFORM-3D software provides three iterative computations, the Newton-Raphson, Direct, and Explicit computations, which can be selected based on material properties. The software also provides a rich material database that contains elastic deformation data, plastic deformation data, thermal energy data, heat exchange data, grain growth, material hardening data, and fracture data for common materials. 


\subsection{Cold Forging Theory}

In order to arrive at a manageable mathematical description of the metal deformation, several simplifying (but reasonable) assumptions are made:

(a) Elastic deformations are neglected.

(b) The deforming material is considered to be in continuum (metallurgical aspects such as grains, grain boundaries, and dislocations are not considered).

(c) Anisotropy and Bauschinger effects are neglected. Volume remains constant. In this study, we assume the workpiece is homogeneous and isotropic, ignoring the effects of direction on stress yield that von Mises asserted should be considered.

(d) Yield criterion

Generally, the von Mises yielding criterion is adopted as a material plastic rule. This yield characterizes the relationship between material yield and 3D stress states. All three axial principal stresses, $\sigma_{1}, \sigma_{2}$ and $\sigma_{3}$, can be expressed as effective stress $\sigma$ in Equation (3).

$$
\bar{\sigma}=\frac{1}{\sqrt{2}}\left[\left(\sigma_{1}-\sigma_{2}\right)^{2}+\left(\sigma_{2}-\sigma_{3}\right)^{2}+\left(\sigma_{3}-\sigma_{1}\right)^{2}\right]^{\frac{1}{2}}
$$

Von Mises notes that when effective stress reaches the material's yield strength value $(Y)$, plastic deformation starts. Equation (3) is expressed as

$$
\bar{\sigma}=\frac{1}{\sqrt{2}}\left[\left(\sigma_{1}-\sigma_{2}\right)^{2}+\left(\sigma_{2}-\sigma_{3}\right)^{2}+\left(\sigma_{3}-\sigma_{1}\right)^{2}\right]^{\frac{1}{2}}=\Upsilon
$$

(e) Friction is expressed by a simplified expression such as Coulomb's law or by a constant shear stress.

\section{Research Methodology}

Thread rolling was simulated with the following objectives in this study.

(a) To predict the required forming load to support the design or selection of proper dies and thread rolling machines.

(b) To model material flow (stress, strain, and velocity field) to evaluate thread plate design and material selection.

(c) To determine simulation parameters to further thread plate design.

The mechanical properties of materials must be analyzed, such as by analyzing cylindrical test results for flow stress, before a flat-die thread rolling simulation can be performed. In the experiment herein, the material AISI (American Iron and Steel Institute) 1022 is firstly cut as is a hex nut to form the test cylindrical sample; the external diameter to length ratio is 1:1.5; the external diameter of the completed cylindrical sample is $3.7 \mathrm{~mm}$, and its height is $5.55 \mathrm{~mm}$. A universal testing machine with 20 tons of pressure is used to perform the compression test; the cylindrical sample is coated with lubricant (MoS2) before compression so the material is tested under conditions close to those of an actual production line.

After 30\%,60\%, 75\%, and 90\% compression of the cylindrical sample, as shown in Figure 5, the computer automatically records the cold forging load, compressing step, and the deformation time. These data are further calculated and organized with Excel and curve fitting, and the true stress-strain equation is found to be $\sigma=625.16 \varepsilon^{016}$ (Figure 6), where the constant 625.16 is the strength coefficient and 0.16 is the hardening index. The higher R-squared 0.9723 , in this study, means the better the model fits the experiments data. 

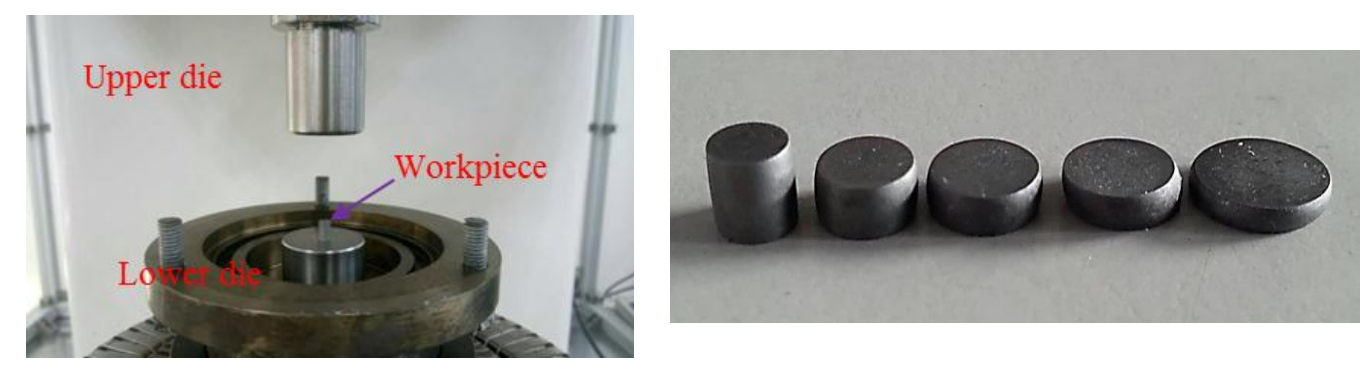

Figure 5. Compression experiment and compressed cylindrical samples at 30\%, 60\%, 75\%, and 90\%.

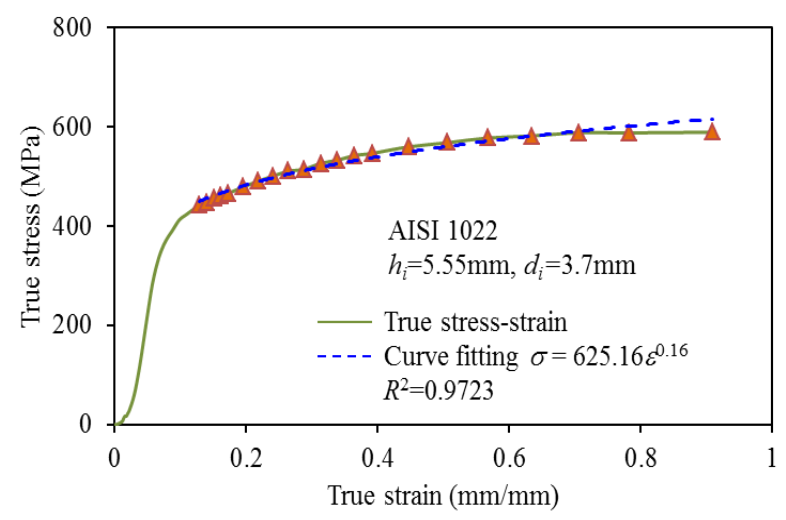

Figure 6. True Stress versus true strain for AISI $1022\left(h_{i}\right.$ is initial height of compressed cylindrical sample, and $d_{i}$ is diameter).

Figure 7 displays the research process. The computer-aided design software SolidWorks was utilized to depict the produced thread rolling plate and to transform it into an STL file for simulation using DEFORM finite element forming analysis software. Table 1 presents the relevant analytic settings. The sheet metal forming process is not easily analyzed and simulated because the fixed thread plate and the sliding thread plate are more complicated than mechanical threads. In the simulation process, the fixed flat die is fixed in all the directions. The moving flat undergoes reciprocation with the workpiece (blank) between them, and shifts towards a fixed direction shown in Figure 3.

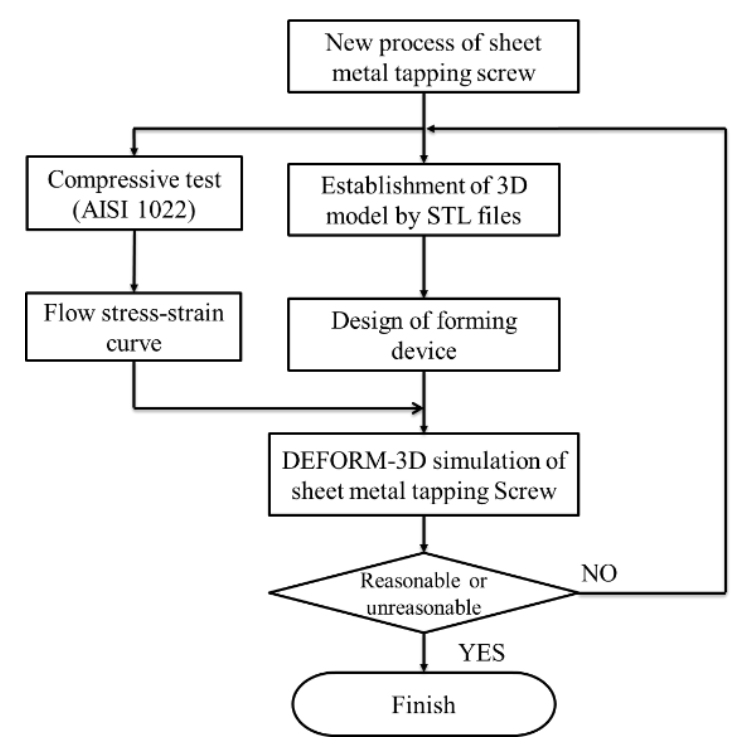

Figure 7. Research flow chart. 
Table 1. DEFORM simulation parameters.

\begin{tabular}{cc}
\hline Type of Mesh Element & Tetrahedron \\
\hline Workpiece material & AISI 1022 \\
Flat dies & SKH 9 \\
True stress-strain curve & $\sigma=625.16 \varepsilon^{0.16}$ \\
Blank/die property & Plastic body $/$ rigid (elastic) body \\
Temperature & $20^{\circ} \mathrm{C}$ \\
Die speed & $10 \mathrm{~mm} / \mathrm{s}$ \\
Mesh number (workpiece/flat die) & $80,000 / 300,000$ \\
\hline
\end{tabular}

In the above analytical process, thread rolling, but not the thermal conduction mode, is taken into account in the preprocessing simulation environment of DEFORM. The blank is a plastic body; the rest of the die is a rigid body, and the planned conditions conform as much as possible to those of real thread rolling in the forming process. In this study, the forming temperature is assumed to be room temperature; temperature variations that arise from plastic deformation of formed pieces during cold forming is small, and the local effects of temperature are therefore ignored. Field observations revealed that four major factors affect the quality of thread rolling and the service life of the thread plates; they are constant shear friction, thread rolling compression (screw thread plate gap), material flow stress (true stress-strain relation), and geometry of the screw thread plate.

\section{Results and Discussion}

The simulation involved 80,000 grid cells owing to the large changes in the workpiece geometry, and the grid around the workpiece was particularly fine (Figure 8). More accurate results could be obtained using a finer grid at the expense of increased computing time. Figure 9 displays the simulated equivalent stress, equivalent strain, and principal stress.
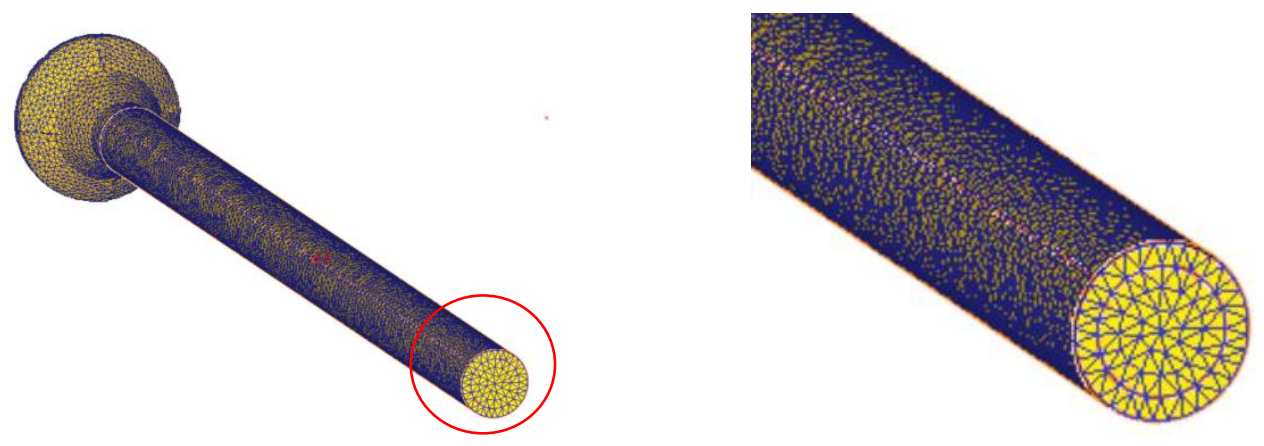

Figure 8. Refined grid around workpiece.

Figure 9a shows the distribution of equivalent stress, whose maximum (1040 MPa) appears on the contact surface between the threading board and the screw. Figure $9 \mathrm{~b}$ presents the distribution of equivalent strain on the screw surface (at the thread forming position) when the sheet metal threading board is compressed into the cone bolt. Therefore, the maximum strain $(14.1 \mathrm{~mm} / \mathrm{mm})$ is reached on the cone bolt. Figure 9c plots the distribution of maximum principal stress. Like the maximum equivalent stress and the maximum equivalent strain, the maximum principal stress (1990 $\mathrm{MPa})$ appears on the contact surface between the threading board and the screw, and is mostly tensile. Compressive stress appears in some areas near the cone bolt. 


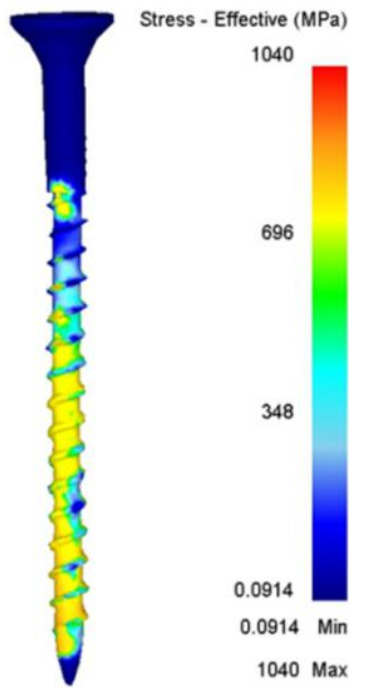

(a) Effective stress

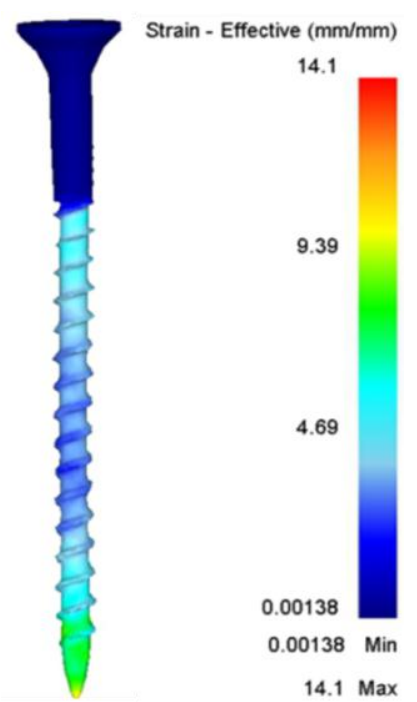

(b) Effective strain

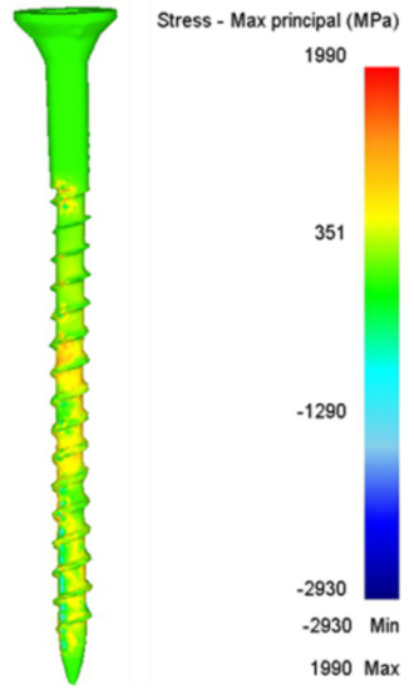

(c) Principal stress

Figure 9. Effective stress, effective strain, and maximum principal stress of a sheet metal tapping screw in $3 \mathrm{D}$.

Figures 10 and 11 compare the actual sheet metal tapping screw before the simulation with that after it; they demonstrate that the simulation exactly captured actual physical deformation. Furthermore, equivalent stress, equivalent strain, velocity field, deformation, and forming load at various deformation stages, which could not be determined on-site, were acquired. Such simulations help mold designers or screw manufacturers to design new sheet metal threads to understand the complete process of thread forming and to search for optimized designs of the threading board without developing molds. Simulations can be carried out to understand and reduce the amount of cut remainders that are formed by compressing sheet metal in the fabrication process to reduce production costs and enhance competitiveness.
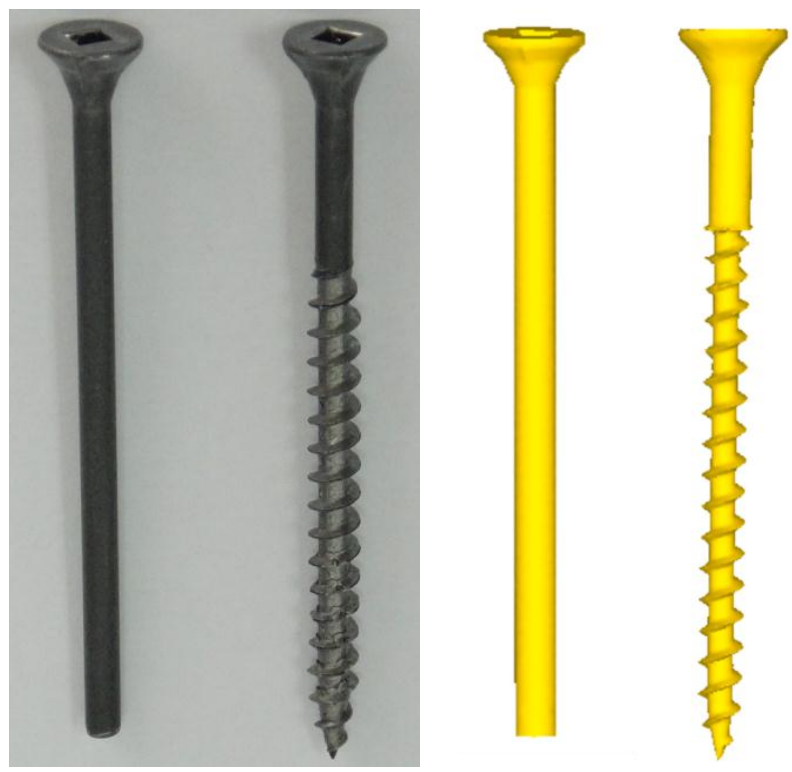

Figure 10. Simulated workpieces and actual sheet metal tapping screw. 

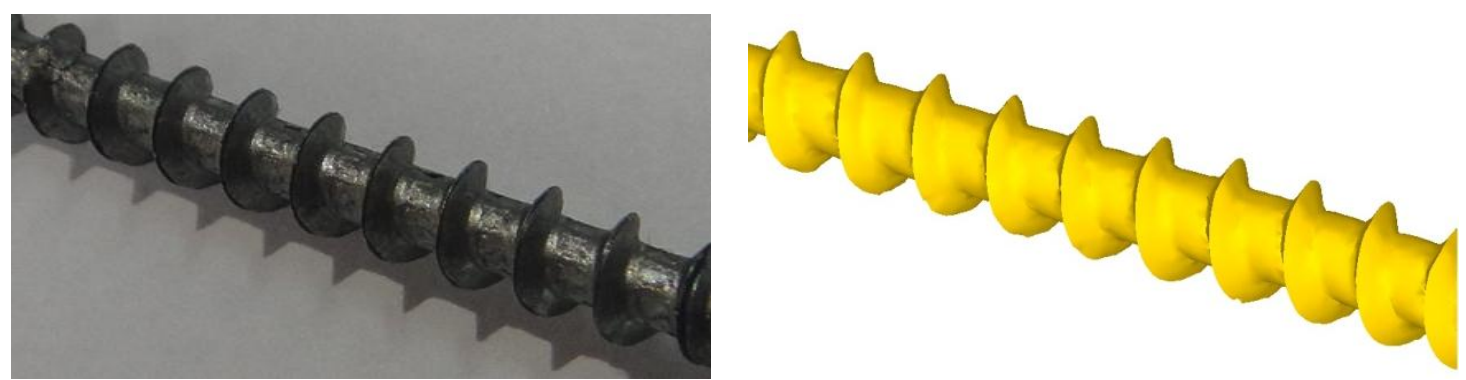

Figure 11. Detail of simulated workpieces and actual sheet metal tapping screw.

Figure 12 shows the simulated forging loads on the moving flat die. The forging load ( $5.88 \mathrm{kN})$ is largest during sheet metal tapping screw forming with a moving flat die.

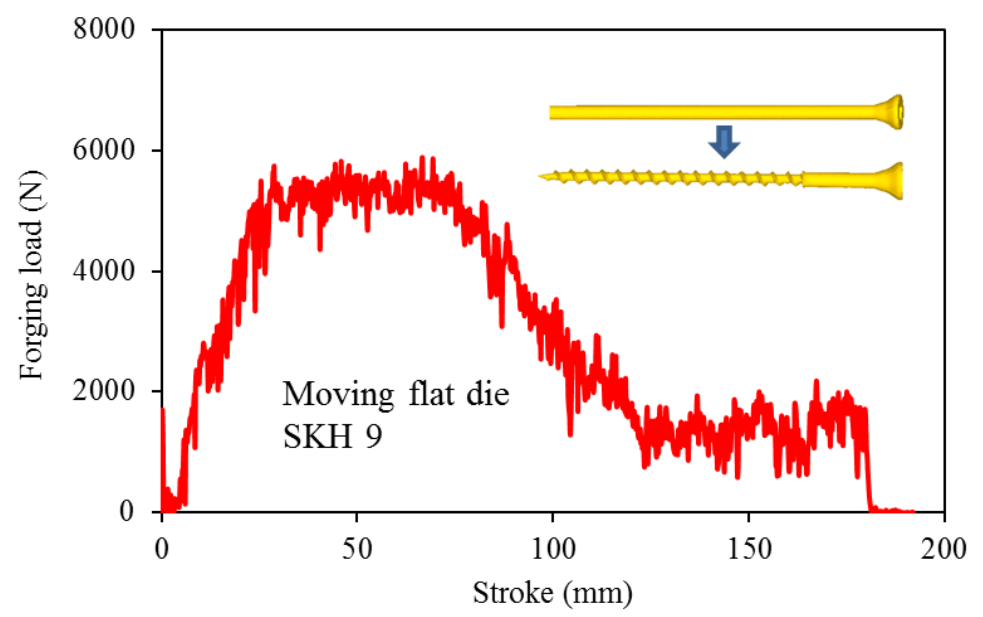

Figure 12. Forging loads on moving flat die.

Figures 13 and 14 plot the effective stresses of the moving flat die, the fixed die and the workpiece at a stroke distance of $8.89 \mathrm{~mm}$. Figure 13 indicates the effective stresses of the moving flat die and the fixed flat die are not equal. From Figure 14, the effective stresses on the cross-section, according to Figure 13, indicates a different distribution of the effective stress situation on the workpiece, moving and fixed flat dies.

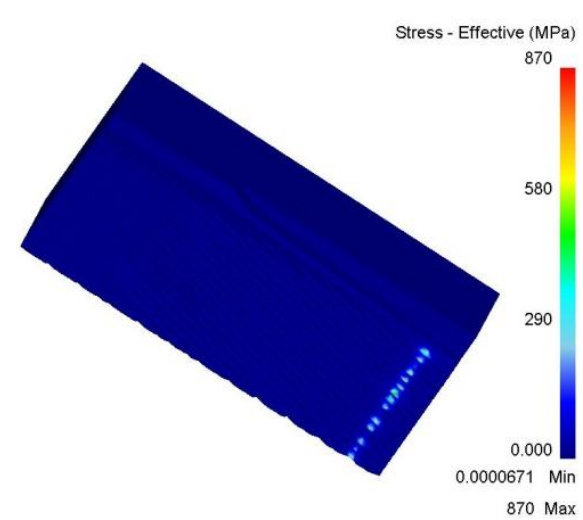

(a) Moving flat die

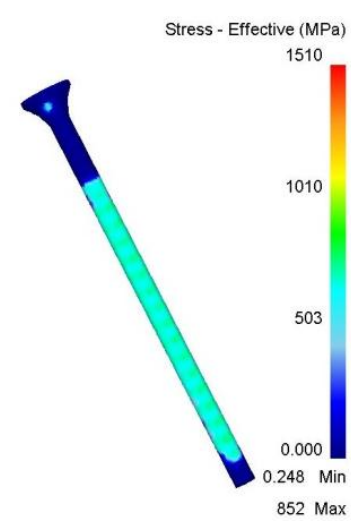

(b) Workpiece

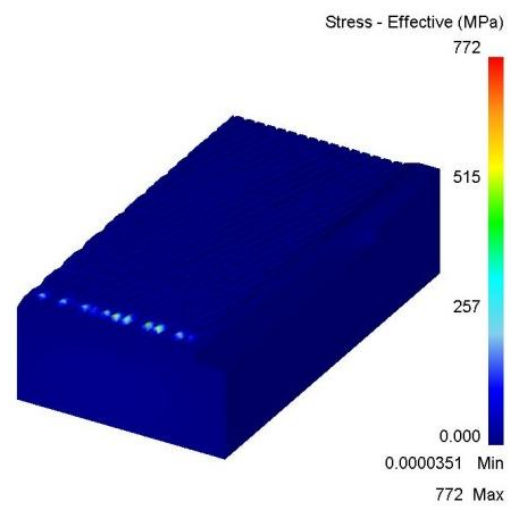

(c) Fixed flat die

Figure 13. Effective stresses of flat dies and workpiece at a stroke distance of $8.89 \mathrm{~mm}$. 


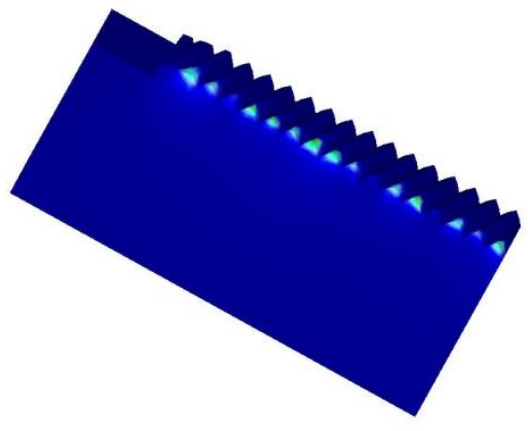

(a) Moving flat die

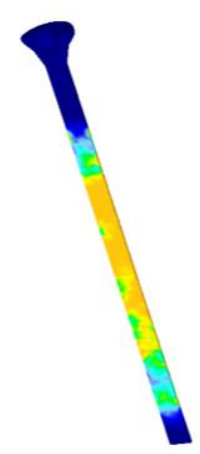

(b) Workpiece

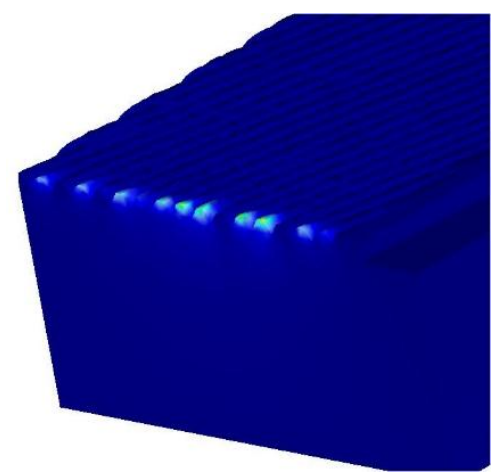

(c) Fixed flat die

Figure 14. Effective stresses of flat dies and workpiece for cross-section of Figure 13.

Figures 15 and 16 plot the effective stresses of the moving flat die, the fixed die and the workpiece at stroke distances of $66.60 \mathrm{~mm}$. Again, the effective stresses of the moving flat die, the fixed flat die and the workpiece are not equal in this case, and the different distribution of the effective stress situation is also displayed in Figure 16. The induced maximum effective stress, $1470 \mathrm{MPa}$, in the fixed flat die does not exceed the yield stress of the die material SKH 9.

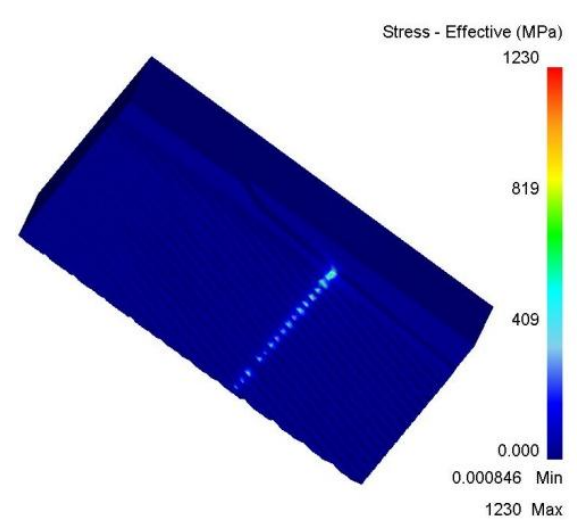

(a) Moving flat die

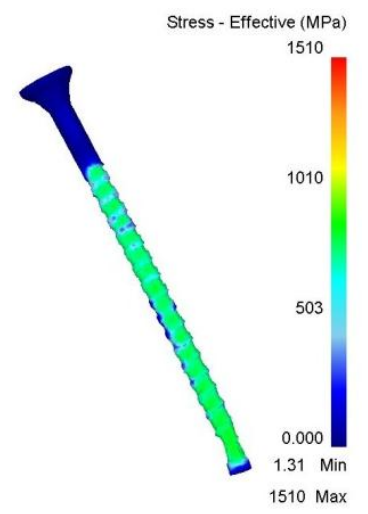

(b) Workpiece

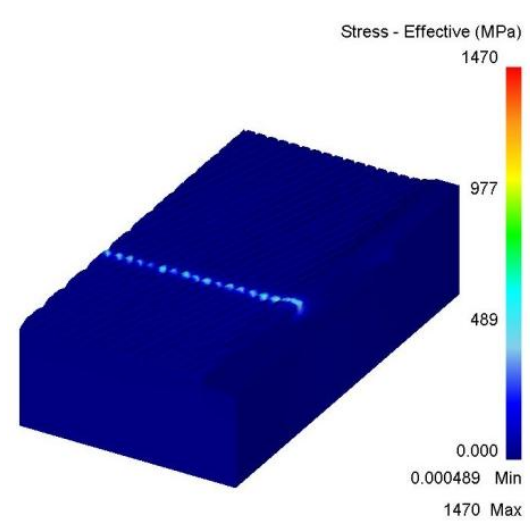

(c) Fixed flat die

Figure 15. Effective stresses of flat dies and the workpiece at a stroke distance of $66.60 \mathrm{~mm}$.

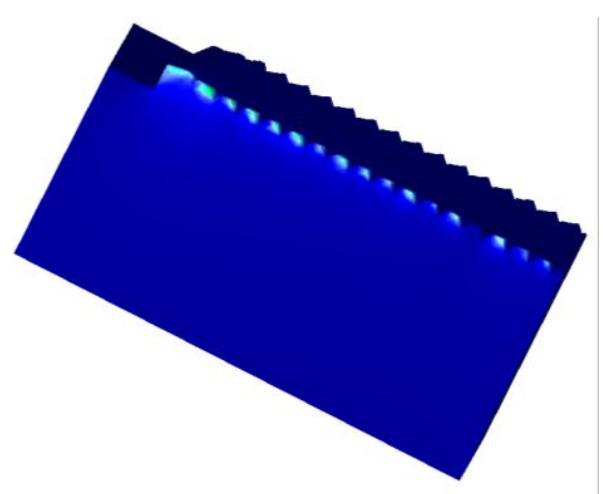

(a) Moving flat die

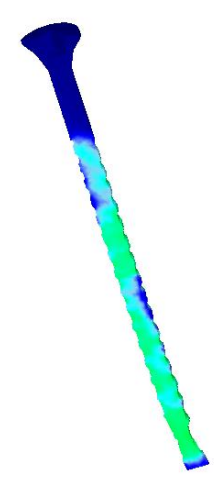

(b) Workpiece

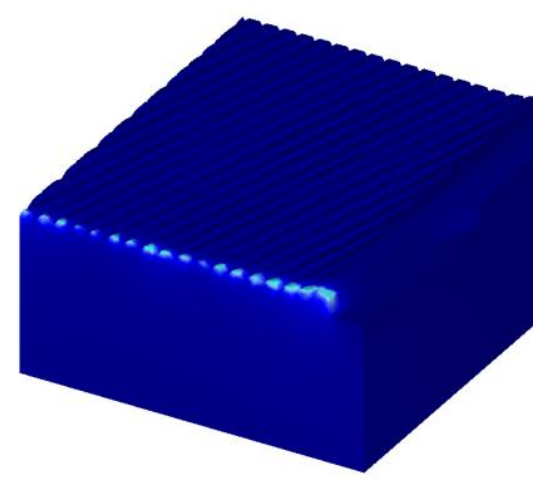

(c) Fixed flat die

Figure 16. Effective stresses of flat dies and workpiece for cross-section of Figure 15.

Table 2 compares the DEFORM-simulated with the mean sizes and standard deviations (SD), based on five dimensions of the actual sheet metal tapping screws; the errors are less than $0.90 \%$, except for the 
error of $3.075 \%$ with sharp angle (A3) owing to its small size. This finding indicates that the accuracy of new product development based on a DEFORM simulation is high. The dimensional accuracies that are obtained from experimental and numerical analyses appear to be consistent and reliable.

Table 2. Comparison of dimensions of simulated and actual products.

\begin{tabular}{cccc}
\hline & & & \\
\hline Dimension & Exp. \pm SD & FEM \pm SD & Error (\%) \\
\hline A1 (mm) & $4.32 \pm 0.0049$ & $4.32 \pm 0.0043$ & 0.085 \\
A2 (mm) & $2.64 \pm 0.0171$ & $2.62 \pm 0.0029$ & 0.884 \\
$\mathrm{~A} 3\left({ }^{\circ}\right)$ & $23.73 \pm 1.0333$ & $24.46 \pm 0.9587$ & 3.075 \\
\hline
\end{tabular}

\section{Conclusions}

Comparing DEFORM simulation results with the actual products in this study yields the following conclusions.

(1) A combination of CAD and CAE can replace the trial-and-error method or worker experience for determining the plastic deformation of screw threading processes.

(2) Comparing simulated and actual sizes of the produced sheet metal tapping screw reveals that the sheet metal tapping screw forging size errors were less than $0.9 \%$, except for the $3.075 \%$ error with a small angle, demonstrating the accuracy of the simulated forming process.

(3) The forming process can be used to reduce the number of die tests and to improve the quality and properties of formed tapping screws.

Acknowledgments: The authors would like to thank the National Science Council of the Republic of China, Taiwan, for financially supporting this research under Contract No. MOST 105-2622-E-244-001-CC3.

Author Contributions: Shao-Yi Hsia designed and performed the experiments and analysis, and wrote the paper; Yu-Tuan Chou and Guan-Fan Lu built up the research project and consulted with the research process.

Conflicts of Interest: The authors declare no conflicts of interest.

\section{References}

1. O'Connell, M.; Painter, B.; Maul, G.; Taylan, A. Flashless closed-die upset forging-load estimation for optimal cold header selection. J. Mater. Process. Technol. 1996, 59, 81-94. [CrossRef]

2. Kim, H.; Altan, T. Cold forging of steel-practical examples of computerized part and process design. J. Mater. Process. Technol. 1996, 59, 122-131. [CrossRef]

3. Liou, J.H.; Jang, D.Y. Forging parameter optimization considering stress distributions in product through FEM analysis and robust design methodology. Int. J. Mach. Tools Manuf. 1997, 37, 775-782. [CrossRef]

4. Joun, M.S.; Lee, S.W.; Chung, J.H. Finite element analysis of a multi-stage axisymmetric forging process. Int. J. Mach. Tools Manuf. 1998, 38, 843-854. [CrossRef]

5. Vazquez, V.; Hannan, D.; Altan, T. Tool life in cold forging-example of design improvement to increase service life. J. Mater. Process. Technol. 2000, 98, 90-96. [CrossRef]

6. Falk, B.; Engel, U.; Geiger, M. Fundamental aspects for the evaluation of the fatigue behavior of cold forging tools. J. Mater. Process. Technol. 2001, 119, 158-164. [CrossRef]

7. Janicek, L.; Petruska, J.; Maros, B.; Rusz, S. Clod forming of bolts without thermal treatment. J. Mater. Process. Technol. 2002, 125-126, 341-346. [CrossRef] 
8. Min, D.; Kim, M. A study on precision cold forging process improvements for the steering yoke of automobiles by the rigid-plastic finite-element method. J. Mater. Process. Technol. 2003, 138, 339-342. [CrossRef]

9. Liu, G.L.; Zhang, B.X.; Hu, L.; Wang, Z.R.; Huang, S.D.; Tang, Q.B. Applications of numerical simulation to the analysis of bulk-forming processes-Case studies. J. Mater. Process. Technol. 2004, 150, 56-61. [CrossRef]

10. Sofuoglu, H.; Gedikli, H. Physical and numerical analysis of three dimensional extrusion process. Comput. Mater. Sci. 2004, 31, 113-124. [CrossRef]

11. Kim, M.S.; Choi, J.C.; Kim, Y.H.; Kim, C.; Park, C.W. The development of an automated process planning and die design system for multi former-bolt products. Int. J. Mach. Tools Manuf. Technol. 2004, 24, $288-297$. [CrossRef]

12. Kim, H.S. A study on cold forging process sequence design of terminal pins for high-voltage capacitors. J. Mater. Process. Technol. 2007, 187-188, 604-608. [CrossRef]

13. Jun, B.Y.; Kang, S.M.; Lee, M.C.; Park, R.H.; Joun, M.S. Prediction of geometric dimensions for cold forgings using the finite element method. J. Mater. Process. Technol. 2007, 189, 459-465. [CrossRef]

14. Lv, C.; Zhang, L.; Mu, Z.; Taib, Q.; Zheng, Q. 3D FEM simulation of the multi-stage forging process of a gas turbine compressor blade. J. Mater. Process. Technol. 2008, 198, 463-470. [CrossRef]

15. Hsia, S.Y. Improved manufacturing process for movable retaining pins using optimization method. Trans. Can. Soc. Mech. Eng. 2015, 39, 379-396.

16. Hsia, S.Y.; Shih, P.Y. Wear improvement of tools in the cold forging process for long hex flange nuts. Materials 2015, 8, 6640-6657. [CrossRef]

17. Landeta, J.F.; Valdivielso, A.F.; de Lacalle, L.L.; Girot, F.; Pérez, J.P. Wear of Form Taps in Threading of Steel Cold Forged Parts. J. Manuf. Sci. Eng. 2015, 137. [CrossRef]

18. Urbikain, G.; Perez, J.M.; de Lacalle, L.N.L.; Andueza, A. Combination of friction drilling and form tapping processes on dissimilar materials for making nutless joints. Proc. Inst. Mech. Eng. B J. Eng. Manuf. 2016. [CrossRef]

(C) 2016 by the authors; licensee MDPI, Basel, Switzerland. This article is an open access article distributed under the terms and conditions of the Creative Commons Attribution (CC-BY) license (http://creativecommons.org/licenses/by/4.0/). 